\title{
Initial osteoblast adhesion and subsequent differentiation on zirconia surfaces are regulated by integrins and heparin-sensitive molecule
}

This article was published in the following Dove Press journal: International Journal of Nanomedicine

Feng Luo ${ }^{1,2}$

Guang Hong ${ }^{3,4}$

Hiroyuki Matsui ${ }^{2}$

Kosei Endo 5

Qianbing Wan'

Keiichi Sasaki ${ }^{2}$

'State Key Laboratory of Oral Diseases, National Clinical Research Center for Oral Diseases, West China Hospital of Stomatology, Sichuan University, Chengdu 6I004I, China; ${ }^{2}$ Division of Advanced Prosthetic Dentistry, Graduate School of Dentistry, Tohoku University, Sendai, Japan; ${ }^{3}$ Liaison Center for Innovative Dentistry, Graduate School of Dentistry, Tohoku University, Sendai, Japan; ${ }^{4}$ Faculty of Dental Medicine, Airlangga University, Surabaya, Indonesia; ${ }^{5}$ Division of Aging and Geriatric Dentistry, Graduate School of Dentistry, Tohoku University, Sendai, Japan

Correspondence: Guang Hong Liaison Center for Innovative Dentistry, Graduate School of Dentistry, Tohoku University, 4-I Seiryo-machi, Aoba-ku, Sendai, 980-8575, Japan

$\mathrm{Tel} / \mathrm{fax}+8|227| 78278$

Email hong@m.tohoku.ac.jp

Qianbing Wan

State Key laboratory of Oral Diseases, National Clinical Research Center for Oral Diseases, West China Hospital of Stomatology, Sichuan University, No I4, Section 3, Renmin Nanlu, Chengdu, 61004I, China

Tel +8628 8550367 I

Fax +862885503474

Email champion@scu.edu.cn
Purpose: It is well known that zirconia materials have good biocompatibility; however, little is known regarding the mechanism by which cells attach to these materials. The purpose of this study is to elucidate the mechanism of cell attachment.

Materials and methods: In this study, we examined the surface characteristics of ceriastabilized zirconia/alumina nanocomposite (NANOZR), yttria-stabilized zirconia (Y-TZP) and commercially pure titanium (CpTi), and we evaluated the initial response of osteoblast-like cells to them with different inhibitors.

Results: Under the same polishing treatment, the three materials, NANOZR, Y-TZP and CpTi, show similar surface wettability but different surface roughness. Osteoblasts could adhere to the surface of all three materials, and spindle shapes were clearer in serum-containing media compared to PBS and serum-free culture media, suggesting that serum-contained proteins are helpful for the initial cell adhesion and spreading. Cell adhesion and proliferation were disrupted in the presence of EDTA. RGD-peptide interfered with cell proliferation by affecting cell protrusion and stress fibers. Monoclonal antibody against non-RGD type integrin $\alpha_{2} \beta_{1}$ enhanced proliferation in Y-TZP, CpTi and culture dish but not in NANOZR. Cell proliferation on NANOZR was specifically inhibited in the presence of heparin. Furthermore, under heparin administration, spindle shape formation was maintained but actin cytoskeleton was disrupted, resulting in loose cellular spreading.

Conclusion: These results suggest that RGD type integrins and heparin-sensitive protein in coordination regulate cell morphology and proliferation on NANOZR, through the regulation of cell polarity and stress fiber formation, respectively.

Keywords: zirconia, biocompatibility, adhesion, RGD-peptide, integrins

\section{Introduction}

In dentistry, zirconia has been used since the early 1990 s for endodontic posts. ${ }^{1}$ Recently, zirconia dental implants were proposed as an important alternative to titanium implants due to their excellent biocompatibility, good esthetics, high corrosion resistance and the absence of allergic reaction. ${ }^{2}$ The biocompatibility of an implant plays an important role in long-term implant success, which is achieved through surface integration with surrounding soft and bone tissues. The biocompatibility of zirconia is very closely related to cell adhesion and behavior on its surface. ${ }^{3}$ The osseointegration properties of biomaterials can be assessed by examining the behavior of osteoblasts on the implant surface. ${ }^{4}$ However, only limited data are available for zirconia-cell interactions, and therefore, studies evaluating zirconia's performance in cell adhesion are needed to support further development of this material for biomedical implant use. 
Cells initially adhere to implant surfaces by attaching either to a pre-adsorbed protein network known as the extracellular matrix (ECM), or to neighboring cells. ${ }^{5}$ The interaction between cell and ECM is mediated by integrin, a heterodimer composed of $\alpha$ and $\beta$ subunits. ${ }^{6,7}$ Furthermore, it is notable that specific integrin heterodimers make different contributions to this process. ${ }^{8}$ For instance, the arginine-glycine-aspartic acid (RGD) sequence in osteopontin plays an important role in cell adhesion and migration. ${ }^{9}$ Conversely, the RGD motif in the primary structure is internally sequestered in the tertiary or quaternary structure of certain ECM, such as fibronectin, vitronectin, collagen and laminin. ${ }^{10}$ Indeed, Olivares-Navarrete et a ${ }^{11}$ recognized that integrin $\alpha_{2} \beta_{1}$ plays a critical role in osteoblast response to micron-scale surface structure and surface energy of titanium substrates. In contrast, syndecans are a small family of trans-membrane proteoglycans that serve as receptors for ECM ligands and growth factors. ${ }^{12}$ Syndecans act as co-receptors for heparin-binding mitogenic growth factors. ${ }^{13}$ It has become increasingly clear that the regulation of cell adhesion and migration are central to integrin-syndecanmediated biological processes. However, the mechanisms of osteoblast adhesion onto zirconia material have not been fully investigated.

The purpose of this study was to elucidate the mechanism of initial osteoblast cell adhesion onto a zirconia surface. Therefore, in this work, we prepared ceria-stabilized zirconia/ alumina nanocomposite (NANOZR), yttria-stabilized zirconia (Y-TZP) and commercially pure titanium (CpTi) specimens, and their surface characteristics were analyzed. Next, MC3T3-E1, osteoblast-like cells were cultured on specimen surfaces in the presence of different culture media and different inhibitors, and the cell numbers and cell morphology were characterized and studied in terms of the initial adhesion and differentiation.

\section{Materials and methods Specimen preparation}

Three kinds of disks $15 \mathrm{~mm}$ in diameter and $1.5 \mathrm{~mm}$ thick of NANOZR (Panasonic Health Care Co, Osaka, Japan), Y-TZP (Panasonic Health Care Co), and CpTi (Nippon Steel Co, Osaka, Japan) were prepared in this study. The surface of each specimen was polished with aluminum oxide waterproof abrasive paper (200\#, 400\#, 600\#). Next, the specimens were cleaned by sonication (SK3200LHC, Kudos, Shanghai, China) in distilled water for 60 minutes and treated with UV light for 24 hours using a $15 \mathrm{~W}$ bactericidal lamp (Toshiba, Tokyo, Japan) followed by immersion in $75 \%$ ethanol for 10 minutes and ultrapure water for 3 minutes.
The specimens were finally stored in an airtight container until further analysis.

\section{Surface characteristics}

The surface morphology of those specimens was observed by scanning electron microscopy (SEM) (JSM-6390LA, Jeol Ltd, Tokyo, Japan) at $15 \mathrm{kV}, 10$-mm working distance, under low pressure $(60 \mathrm{~Pa})$, and under both low $(1,000 \times)$ and high magnification $(5,000 \times)$. The elemental composition of the materials was determined by energy dispersive X-ray analysis (EDS). The surface roughness was measured by profilometer (Surfcom 480A, Accretech, Tokyo, Japan) with a tracing length of $4.0 \mathrm{~mm}$ and a cutoff value of $0.8 \mathrm{~mm}$. The arithmetic average roughness $\left(\mathrm{R}_{\mathrm{a}}\right)$ and ten-point average roughness $\left(R_{z}\right)$ of each material was calculated from a total of 15 points on all three specimens.

The surface wettability of the three materials was examined with a portable contact angle meter (PCA-1; Kyowa Interface Science, Saitama, Japan). The contact angle, surface tension and surface energy of NANOZR, Y-TZP, and CpTi were measured with distilled water, ethylene glycol and formamide (Wako Pure Chemical Industries, Osaka, Japan) as previously reported. ${ }^{14} \mathrm{An}$ auto pipetter and a goniometer were employed to ensure uniformity of distilled water droplet volume $(2 \mu \mathrm{L})$. Images were analyzed with FAMAS software (Kyowa Interface Science, Tokyo, Japan). Three measurements were taken from each of the specimens per substrate. Five random regions were imaged for each specimen.

\section{Cell culture}

MC3T3-E1 osteoblast-like cells (MC3T3-E1: ATCC CRL2594) were utilized for cell culture studies. Cells were cultured in alpha-modified minimum essential medium ( $\alpha$-MEM, Nacalai tesque, Kyoto, Japan) supplemented with $10 \%$ fetal bovine serum (FBS, Gibco Life Technologies Inc., Grand Island, NY, USA) and 1\% penicillin-streptomycin (Gibco Life Technologies Inc.). Cells were maintained at $37^{\circ} \mathrm{C}, 5 \% \mathrm{CO}_{2}$ and $95 \%$ humidity. The medium was changed twice a week, and the cells were passaged at $80 \%$ confluence with the use of $0.25 \%$ Trypsin-EDTA (Gibco Life Technologies Inc.).

\section{Effect of serum-contained proteins}

The specimens were treated as previously described and immersed into phosphate buffered saline (PBS, Gibco Life Technologies Inc.) for 10 minutes just before the experiment. To determine the effect of protein on cell adhesion, MC3T3-E1 cells (2,000 cells/well) were seeded onto NANOZR, Y-TZP and CpTi specimen surfaces and cultured 
in three different culture media: PBS, $\alpha$-MEM, and $\alpha$-MEM supplemented with $10 \%$ FBS.

After 24 hours of incubation, the adhered cells were fixed with $4 \%$ paraformaldehyde for 2 hours at room temperature. Next, the cells were washed twice with PBS, permeabilized using $0.1 \%(\mathrm{v} / \mathrm{v})$ Triton X-100 in PBS for 5 minutes and blocked with $1 \%$ bovine serum albumin (BSA; SigmaAldrich Co., St Louis, MO, USA) in PBS for 30 minutes. After washing twice with PBS, the cells were incubated with $200 \mu \mathrm{L}$ of $100 \mathrm{nM}$ rhodamine-phalloidin (Cytoskeleton Inc., Denver, CO, USA) for 30 minutes to stain F-actin. The cell nuclei were further stained with $200 \mu \mathrm{L}$ of DAPI Fluoromount-G (DAPI; Southern Biotech Co., Birmingham, AL, USA) for 30 seconds. Confocal images of cytoskeletal F-actin and cell nuclei were obtained using laser scanning confocal fluorescence microscopy (LSCFM, LSM 780, Carl Zeiss Meditec AG [Jena, Germany]). The cells cultured for 24 hours were fixed with $4 \%$ paraformaldehyde for 15 minutes at room temperature, rinsed with $1 \mathrm{~mL} /$ well of pure water and stained with $1 \mathrm{~mL} /$ well of eosin staining solution for 1 minute. Then, the cells were rinsed with pure water and dried to observe under inverted microscopy.

The cells' morphology was further observed by SEM. Briefly, the adhered cells were fixed with glutaraldehyde (Wako Pure Chemical Industries) overnight, rinsed with PBS three times and dehydrated in a graded series of ethanol (15 minutes and once for $0 \%, 60 \%, 70 \%, 80 \%, 90 \%, 95 \%$, 2 minutes and twice for $100 \%$ ). Finally, after sputter coating with gold-palladium, the specimens were examined at $15 \mathrm{kV}$ by SEM. Images were recorded at $1,000 \times$ magnification.

\section{Antibodies}

0.5 M ULTRAPURETM EDTA (0.5 M) was obtained from Thermo Fisher Scientific (Waltham, MA, USA). A broad inhibitor of integrins, RGD-peptide (S8008), was purchased from Selleck Chemicals (Houston, TX, USA). The BHA2.1 monoclonal antibody MAB1998 specifically recognizes the $\alpha_{2} \beta_{1}$ integrin complex and was obtained from Millipore (Billerica, MA, USA). Anti-rabbit IgG and HRP-linked antibody (\#7074) were purchased from Cell Signaling Technology, Inc. (Danvers, MA, USA). Heparin (sodium salt, from porcine intestinal mucosa, H3149-10KU) was purchased from Sigma Aldrich Co.

\section{Inhibition assay}

For inhibition of cell attachment, MC3T3-E1 cells were incubated at $37^{\circ} \mathrm{C}$ for 24 hours in the presence of $5 \mathrm{mM}$ EDTA, 1,000 $\mu \mathrm{M}$ RGD, $10 \mu \mathrm{g} / \mathrm{mL}$ MAB1998, $0.2 \mu \mathrm{L} \mathrm{IgG,} \mathrm{and}$ $10 \mu \mathrm{g} / \mathrm{mL}$ heparin. Next, the cells $(500 \mu \mathrm{L}, 5,000$ cells/well) were added to the wells and incubated for 24 hours. To measure cell proliferation on the specimens, a metabolic activity cell counting kit (CCK-8, Dojindo, Kumamoto, Japan) assay was used in this experiment. CCK-8 reagent $(50 \mu \mathrm{L})$ was added into a 24 -well plate and incubated for 2 hours. After that step, $100 \mu \mathrm{L}$ of the reaction product was added into a 96-well plate, and optical density was measured with a microplate reader (Bio-RAD iMark Microplate Reader, Hercules, CA, USA) at a wavelength of $450 \mathrm{~nm}$. The specimens were gently washed in fresh medium and later placed back into the 24-well plate. The cells were stained with rhodamine-phalloidin and DAPI, and the cytoskeletal actin and cell nucleus were observed by LSCFM. Then, the cell surface area ratio was studied to quantify the difference in cell behavior. The cultured cells were fixed with $4 \%$ paraformaldehyde, stained with eosin staining solution and observed under inverted microscopy. The cell morphology and attachment were also examined using SEM as previously described. A 24-well plate (Plate, Thermo Fisher Scientific) without specimens was taken as a control group. All assays were performed in triplicate with each experiment repeated at least three times.

\section{Statistical analysis}

Statistical analysis was performed independently using Student's $t$-test, and one-way analysis of variance (ANOVA) combined with a Student-Newman-Keuls (SNK) multiple comparison test. The differences were considered to be significant when $P<0.05$ and very significant when $P<0.01$.

\section{Results Surface characteristics}

The chemical composition analysis results (Figure 1) show CpTi is composed of $90.92 \%$ titanium and $6.74 \%$ oxygen; NANOZR contains $53.85 \%$ zirconium, $27.58 \%$ aluminum, $12.65 \%$ oxygen and $3.97 \%$ cerium; while Y-TZP is made of $61.17 \%$ zirconium, $7.59 \%$ oxygen and $29.28 \%$ ytterbium. All three materials also contain carbon, which may be due to the polishing and exposure to air.

SEM graphics (Figure 2) of NANOZR, Y-TZP, and $\mathrm{CpTi}$ reveal similar surface scratching after polishing. However, the $\mathrm{R}_{\mathrm{a}}$ and $\mathrm{R}_{\mathrm{z}}$ (Figure 3 ) of NANOZR and Y-TZP are $0.08573 \mu \mathrm{m}$ and $0.8842 \mu \mathrm{m}, 0.0854 \mu \mathrm{m}$ and $0.7587 \mu \mathrm{m}$, values significantly $(P<0.05)$ lower than CpTi's $0.2542 \mu \mathrm{m}$ and $1.46 \mu \mathrm{m}$, respectively, which means the NANOZR and Y-TZP have a flatter surface.

The water contact angles (Figure 4A) of NANOZR, Y-TZP, and CpTi show no significant difference between the materials $(P>0.05)$. The surface energy (Figure 4B) 

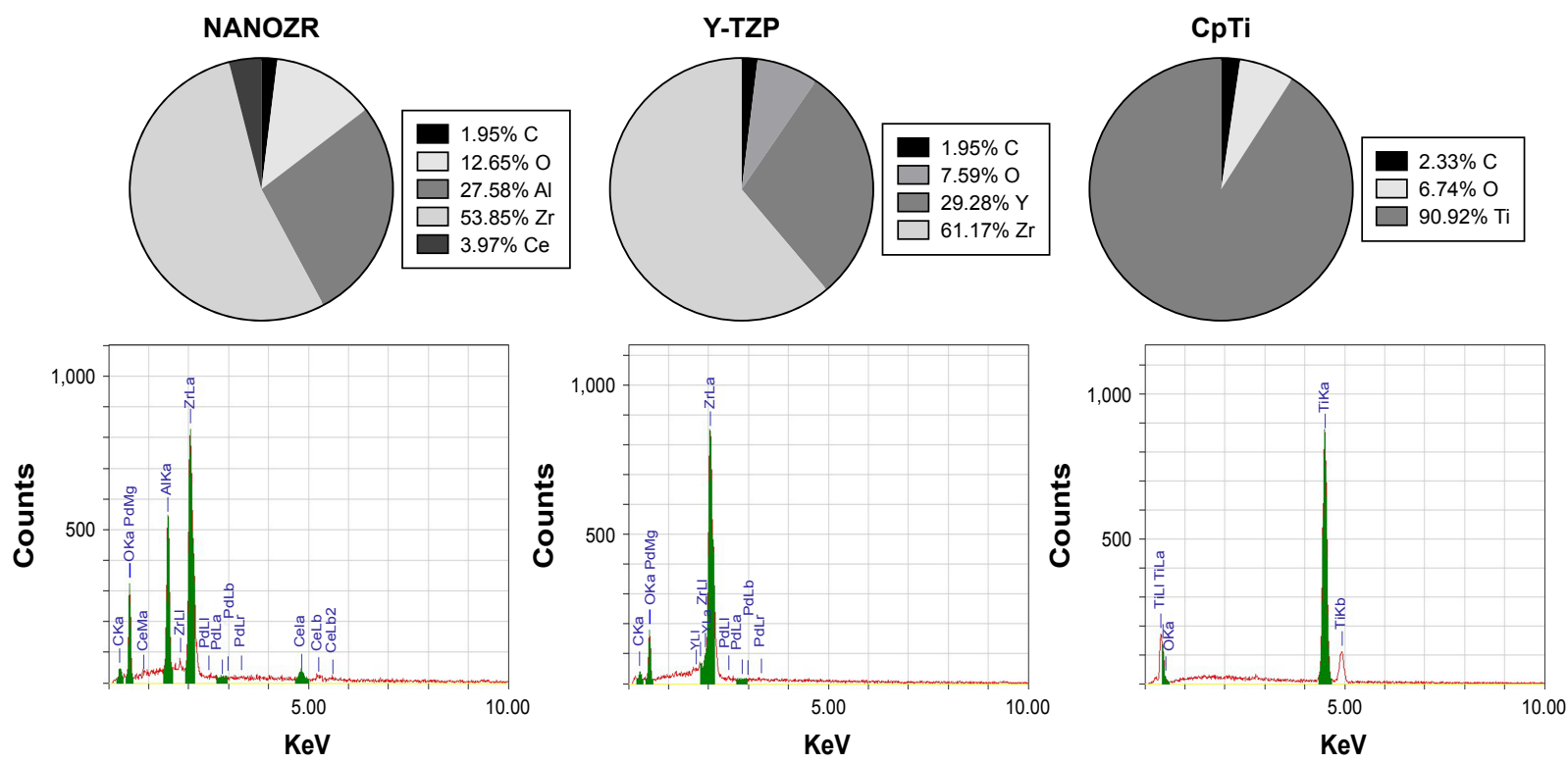

Figure I Chemical composition of the three materials.

Notes: $\mathrm{CPTi}_{\mathrm{P}}$ is composed of $90.92 \%$ titanium and $6.74 \%$ oxygen; NANOZR contains $53.85 \%$ zirconium, $27.58 \%$ aluminum, $12.65 \%$ oxygen and $3.97 \%$ cerium; while $\mathrm{Y}$-TZP is made of $61.17 \%$ zirconium, $7.59 \%$ oxygen and $29.28 \%$ ytterbium. All three materials also contain carbon.

\section{A}
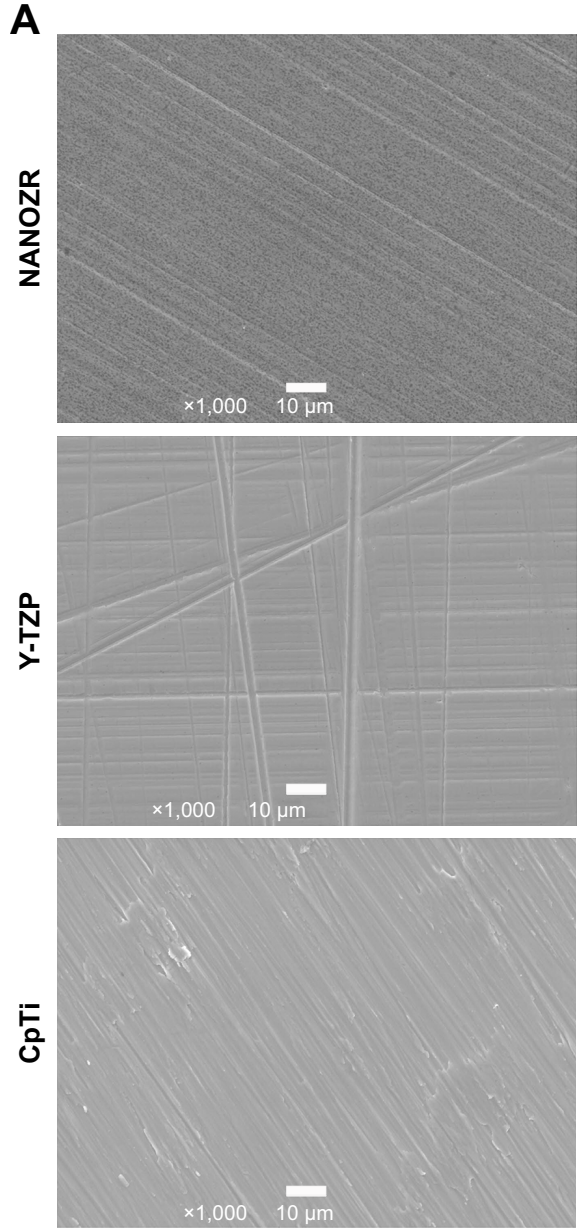

B
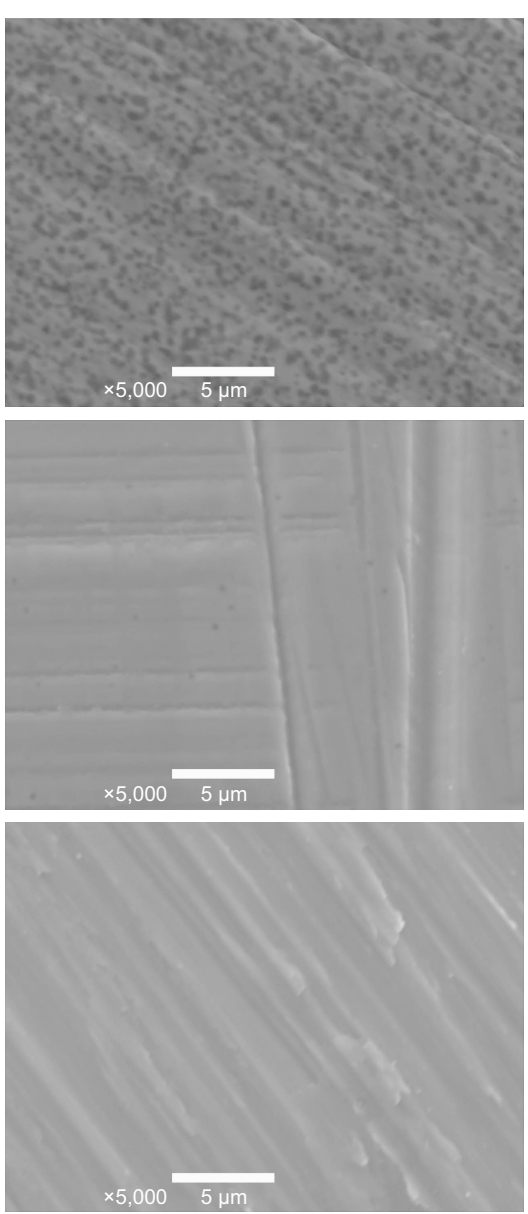

Figure 2 Surface morphology of NANOZR, Y-TZP and CPTi.

Notes: Scanning electron microscopy graphics of NANOZR, Y-TZP, and CpTi reveal similar surface scratching after polishing. Magnification: (A) I,000×, (B) 5,000×. 

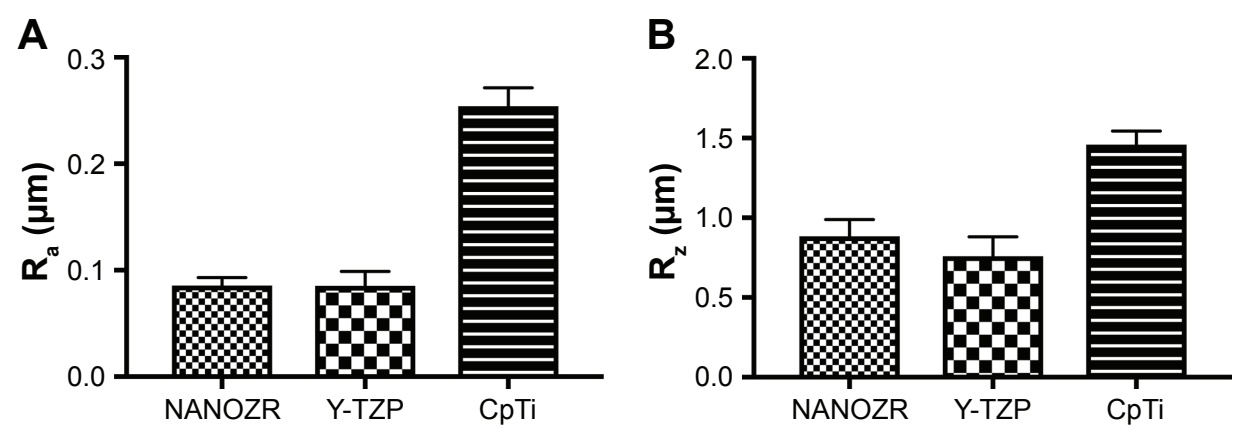

Figure 3 Surface roughness of NANOZR, Y-TZP and CPTi.

Notes: The $R_{a}$ and $R_{z}$ of NANOZR and $Y$-TZP are $0.08573 \mu \mathrm{m}$ and $0.8842 \mu \mathrm{m}, 0.0854 \mu \mathrm{m}$ and $0.7587 \mu \mathrm{m}$, which are significantly $(P<0.05)$ lower than $C_{p}$ Ti's $0.2542 \mu \mathrm{m}$ and I.46 $\mu \mathrm{m}$, respectively. (A) $R_{a} ;$ (B) $R_{z}$.

were analyzed with the Kaelble-Uy theoretical method, and the values were $57.5,62.7$ and $45.96 \mathrm{~mJ} / \mathrm{m}^{2}$ respectively, with no significant difference among them $(P>0.05)$. The surface tension (Figure 4C) of NANOZR, Y-TZP and CpTi were $70.176,70.6$ and $70.94 \mathrm{mN} / \mathrm{m}$ respectively, with no significant difference among them $(P>0.05)$.

\section{Effect of serum-contained proteins}

After 24 hours' incubation in $\alpha$-MEM supplemented with $10 \%$ FBS culture medium, LSCFM and SEM results show highly organized actin stress fibers and actin and spindleshaped cells for all the specimens (Figures 5-7). After being cultured with $\alpha$-MEM, the cells on the surface of
NANOZR and CpTi were spindle shaped, while for the Y-TZP surfaces, the cells were round or oval. After culturing with PBS for 24 hours, the cells were round in shape without obvious cell structure or cytoplasmic process for all of those materials. The cell numbers also decreased obviously.

\section{Effect of inhibitors}

According to the CCK-8 assay results (Figure 8), the cells on the plate showed vulnerability to all inhibitors. It was shown that the absorbance value of cells cultured on the plate without inhibitors was significant lower than when cultured with MAB1988, was significant higher than when cultured
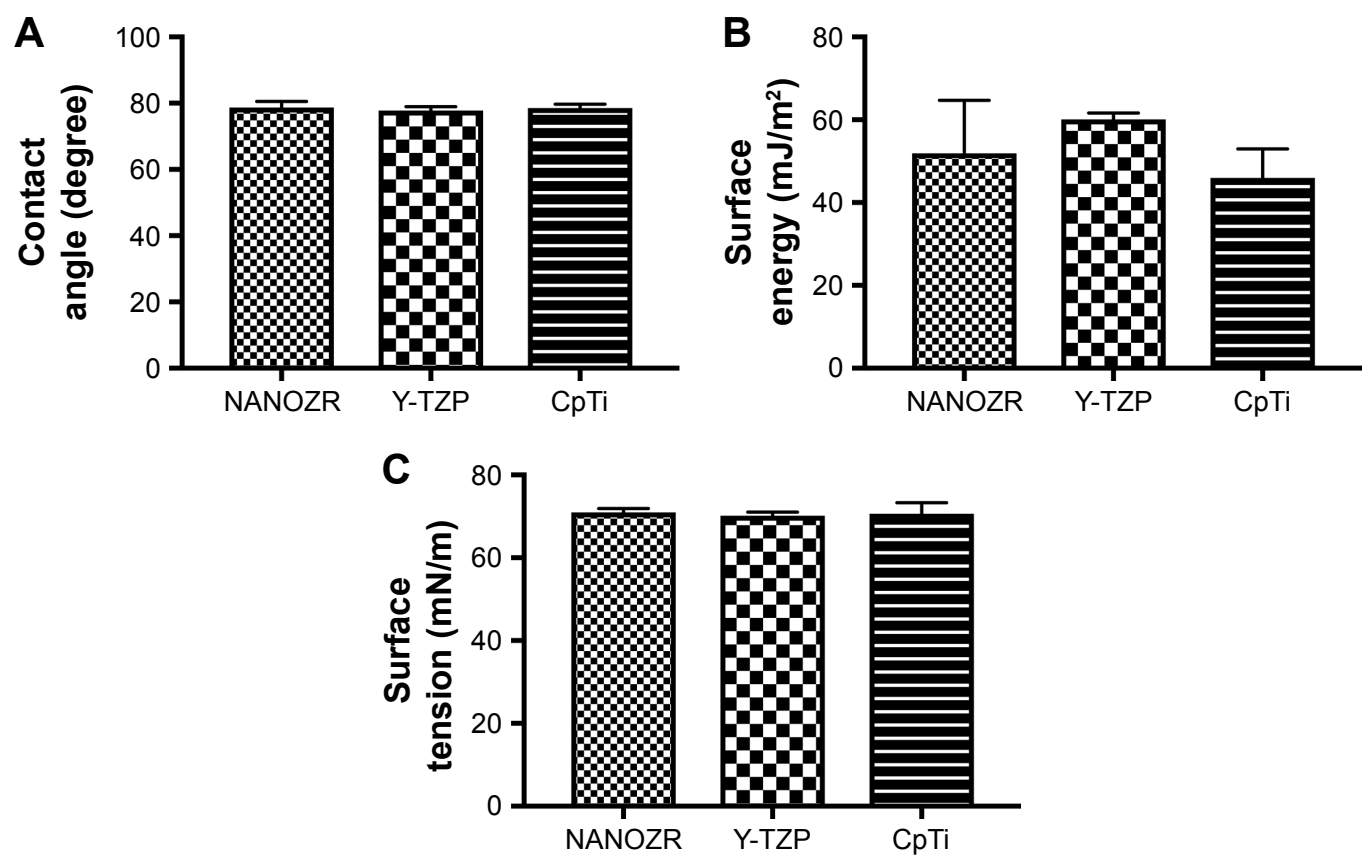

Figure 4 Surface wettability of NANOZR, Y-TZP and CPTi.

Notes: (A) The water contact angles of NANOZR, Y-TZP, and CPTi show no significant difference between the materials ( $P>0.05)$; (B) The surface energy of NANOZR, $3 Y-T Z P$ and CpTi was 57.5, 62.7 and $45.96 \mathrm{~mJ} / \mathrm{m}^{2}$, respectively, with no significant difference among them (P>0.05). (C) The surface tension of NANOZR, $3 Y-T Z P$ and CpTi was $70.176,70.6$ and $70.94 \mathrm{mN} / \mathrm{m}$, respectively, with no significant difference among them $(P>0.05)$. 

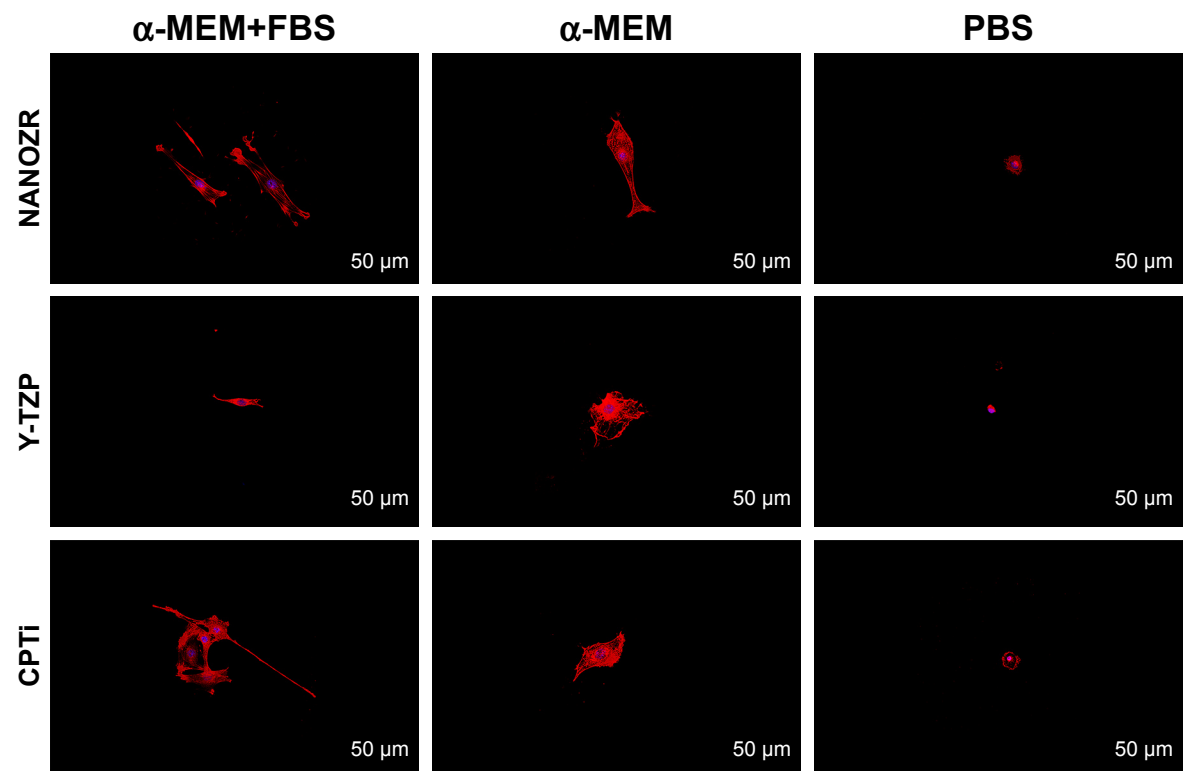

Figure 5 Observation of actin cytoskeleton and nucleus of MC3T3-EI cells cultured in three different culture media: PBS, $\alpha$-MEM, and $\alpha-M E M$ supplemented with I0\% FBS, on all surfaces after 24 hours of incubation.

with EDTA and IgG, and showed no significant difference for RGD and Heparin. As Figure 8A shows, a significant decrease $(P<0.05)$ in cell number was found compared to the control group after culturing cells with EDTA. Further, rhodamine-phalloidin and DAPI staining (Figure 9), SEM (Figure 10) and eosin staining (Figure 11) results showed that the cells cultured with EDTA displayed weak and poorly structured actin filaments.
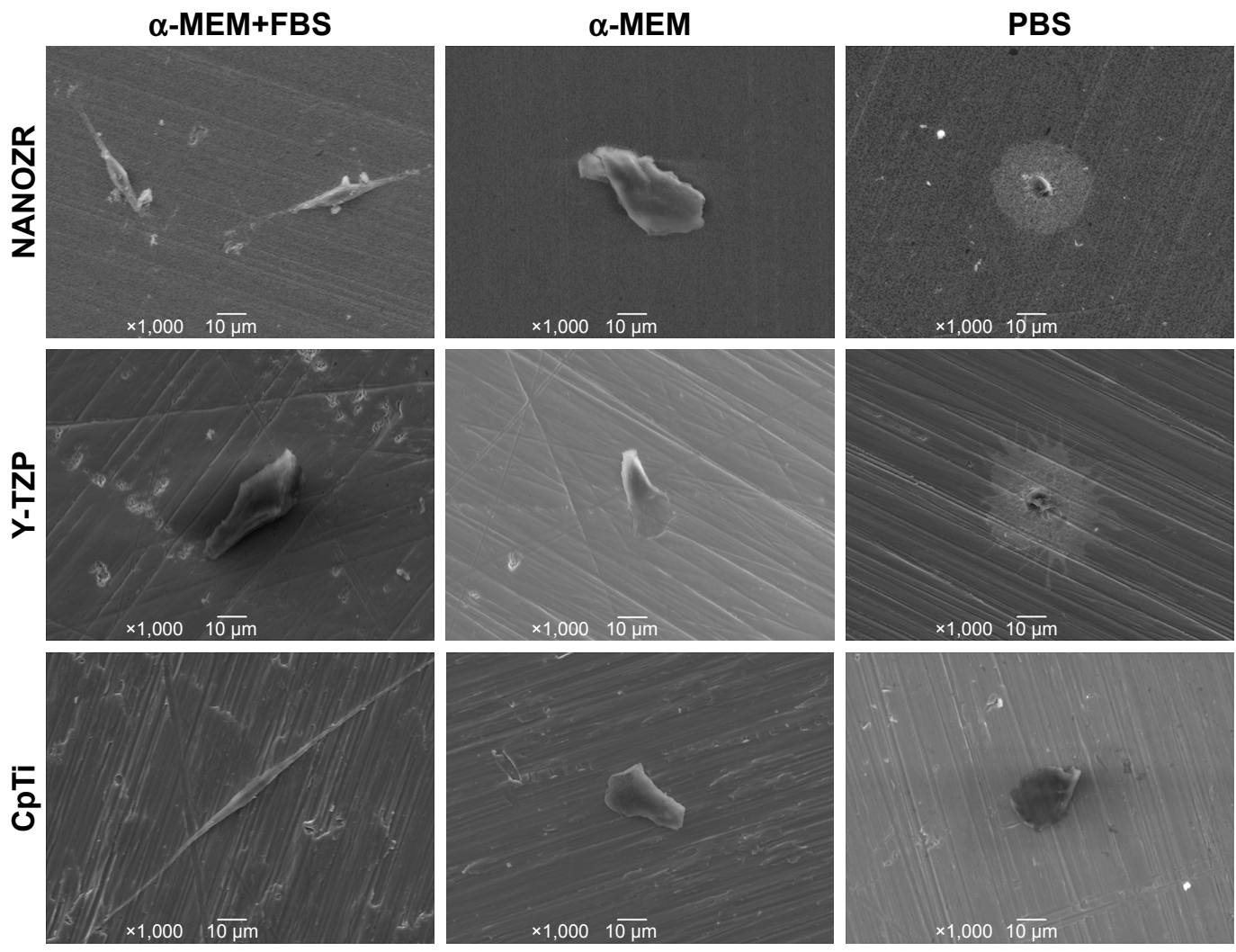

Figure 6 Scanning electron microscopy observation of MC3T3-EI cells cultured in three different culture media: PBS, $\alpha$-MEM, and $\alpha$-MEM supplemented with $10 \%$ FBS, on all surfaces after 24 hours of incubation. Magnification: I,000X 


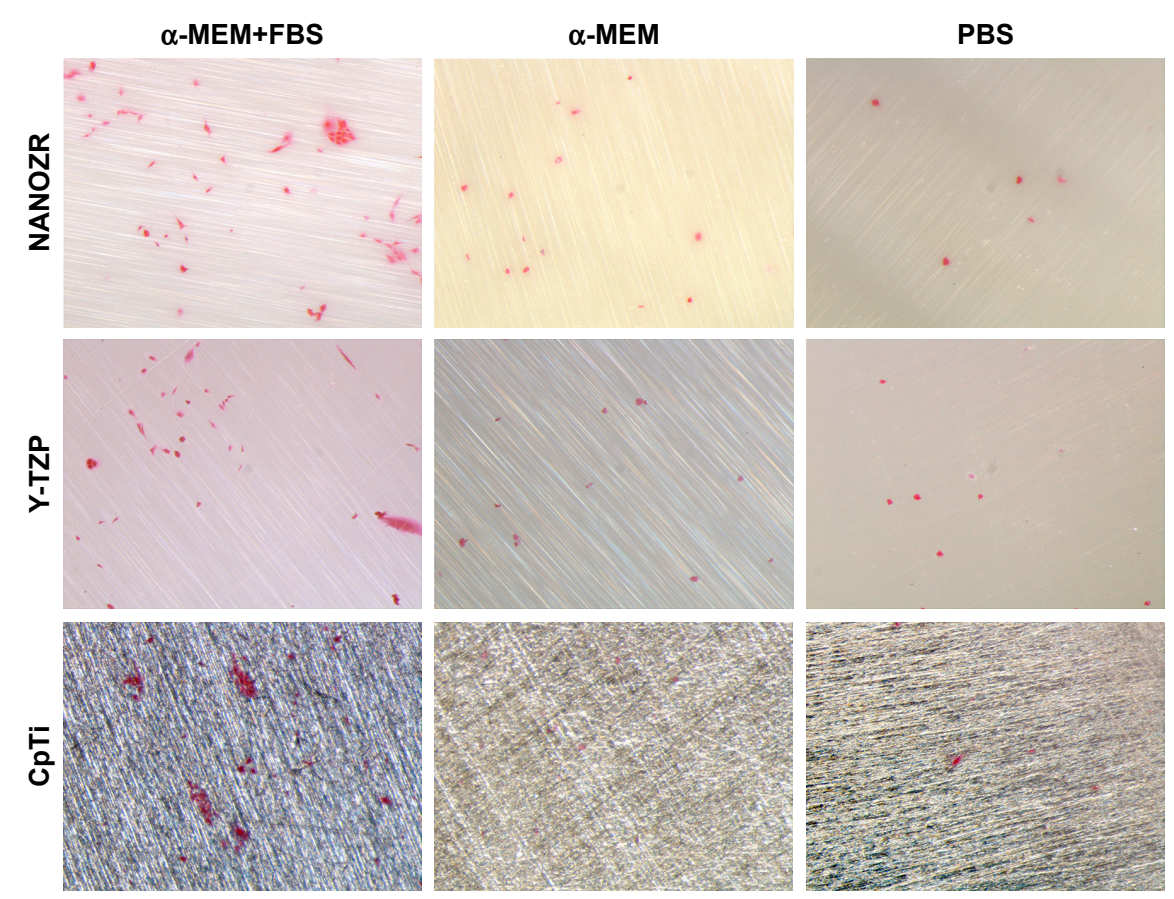

Figure 7 Observation of cell morphology by eosin staining in three different culture media: PBS, $\alpha-$ MEM, and $\alpha-$ MEM supplemented with $10 \%$ FBS, on all surfaces after 24 hours of incubation. Magnification: 5.6x.

A similar decreasing trend was observed for cells cultured with RGD and IgG for 24 hours (Figure $8 \mathrm{~B}$ and D), and the difference was statistically significant $(P<0.05)$. In contrast, there was a significant increase $(P<0.05)$ in the proliferation of MC3T3-E1 cells cultured on the surface of Y-TZP, CpTi and Plate, while for NANOZR the difference was not statically significant, but still showed an increase trend. As shown in Figures 9-11, the RGD and MAB1998 groups display relatively complete cytoskeletal F-actin and cell nucleus structure. Cell-cell contacts and numerous filopodia-like processes were also observed.

Culturing MC3T3-E1 in the presence of Heparin (Figure 8E), the decrease in cell number compared to control group was not significant $(P>0.05)$. However, the cells
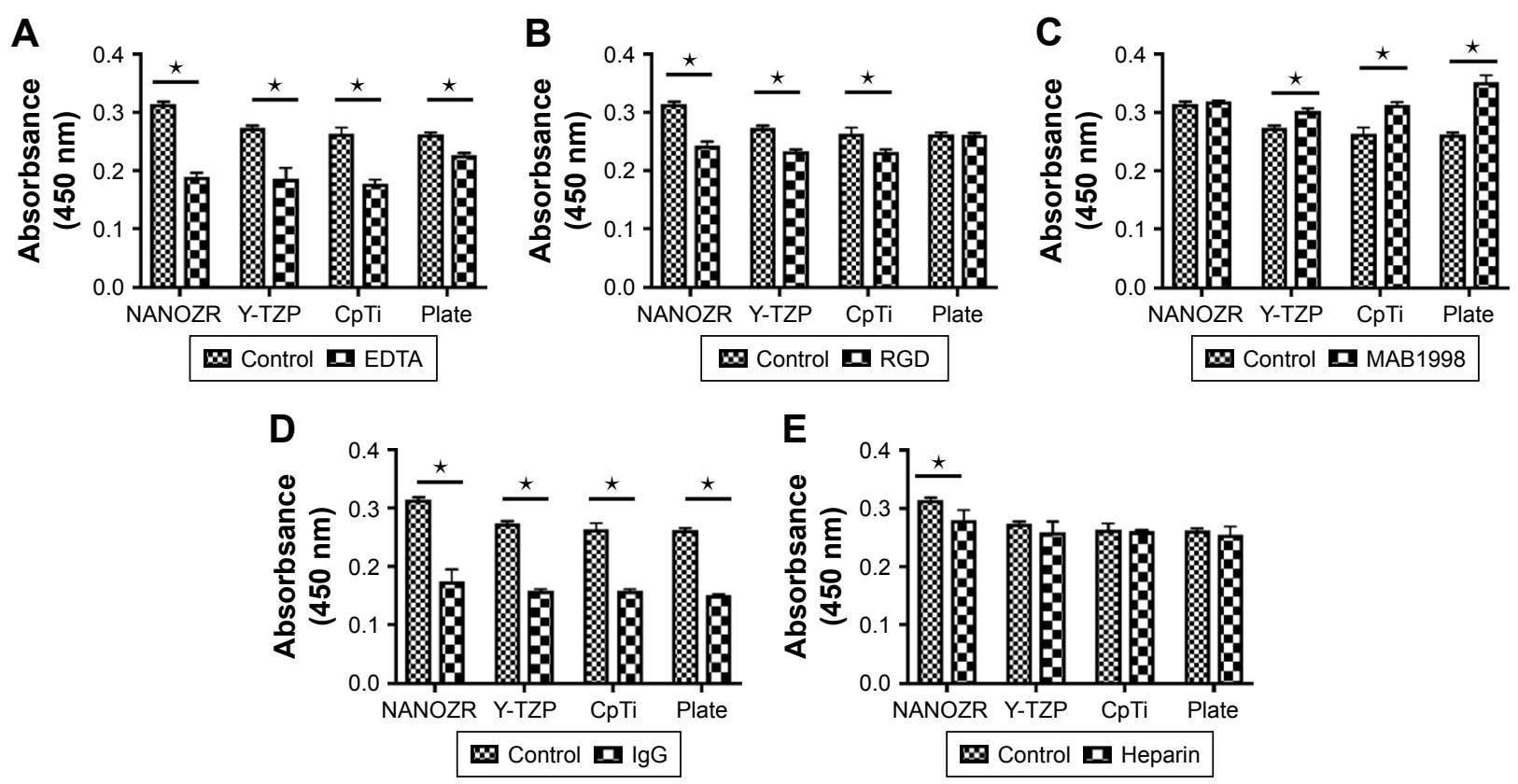

Figure 8 Cell proliferation of osteoblasts (MC3T3-EI cells) cultured in the presence of different inhibitors after 24 hours of incubation. Notes: (A) EDTA; (B) RGD; (C) MABI998; (D) lgG; (E) Heparin. $\star$ Indicates the difference between the two groups is significant (P<0.05). 

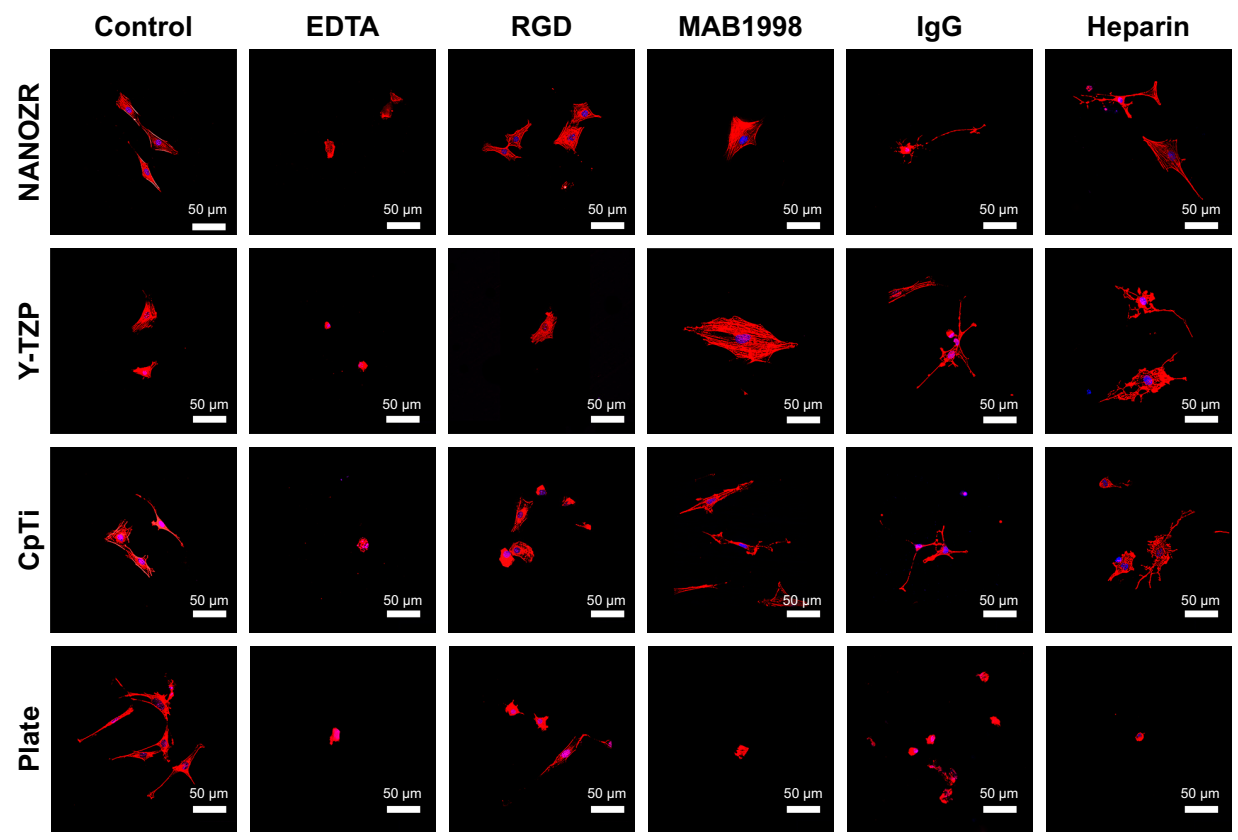

Figure 9 Observation of actin cytoskeleton and nucleus of MC3T3-EI cells cultured in the presence of different inhibitors (Control, EDTA, RGD, MABI998, IgG and Heparin) after 24 hours of incubation.

cultured with heparin displayed weak and poorly structured actin filaments (Figures 9-11). In addition, cell-cell contacts and numerous filopodia-like processes were not evident.

As shown in Figure 12, the cell surface area ratios of RGD and MAB1998 groups are higher than EDTA, IgG and Heparin groups. In addition, the results of NANOZR, Y-TZP and $\mathrm{CpTi}$ are better than Plate.

\section{Discussion}

Biomaterials for implantation in bone should evoke favorable cellular responses in terms of cell attachment, adhesion, proliferation and differentiation. In particular, the initial phase of cell/material interactions and the quality of this stage will influence the cell's capacity to proliferate and differentiate. ${ }^{15}$ Therefore, the quality of cell adhesion seems
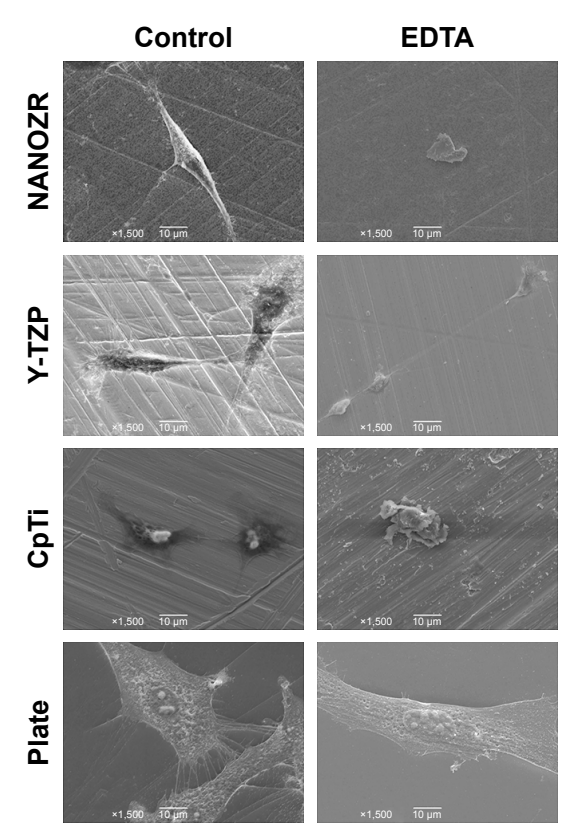
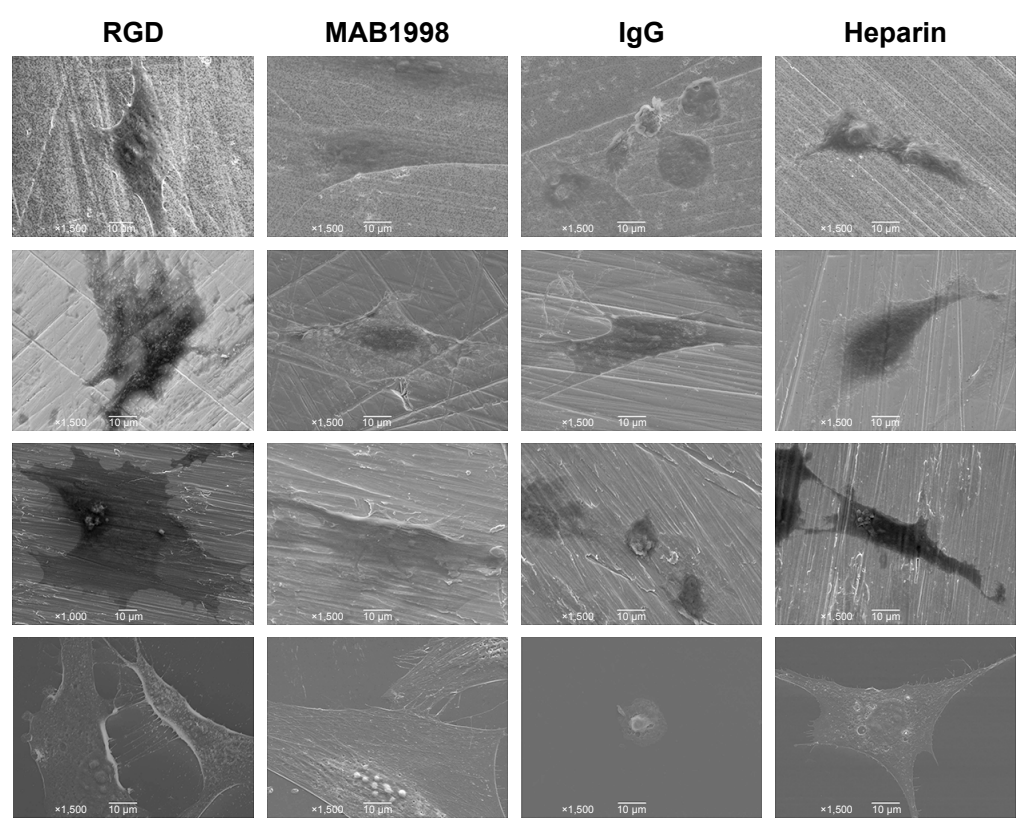

Figure 10 Scanning electron microscopy observation of MC3T3-EI cells cultured in the presence of different inhibitors (Control, EDTA, RGD, MABI998, IgG and Heparin) after 24 hours of incubation. Magnification: I,500x. 


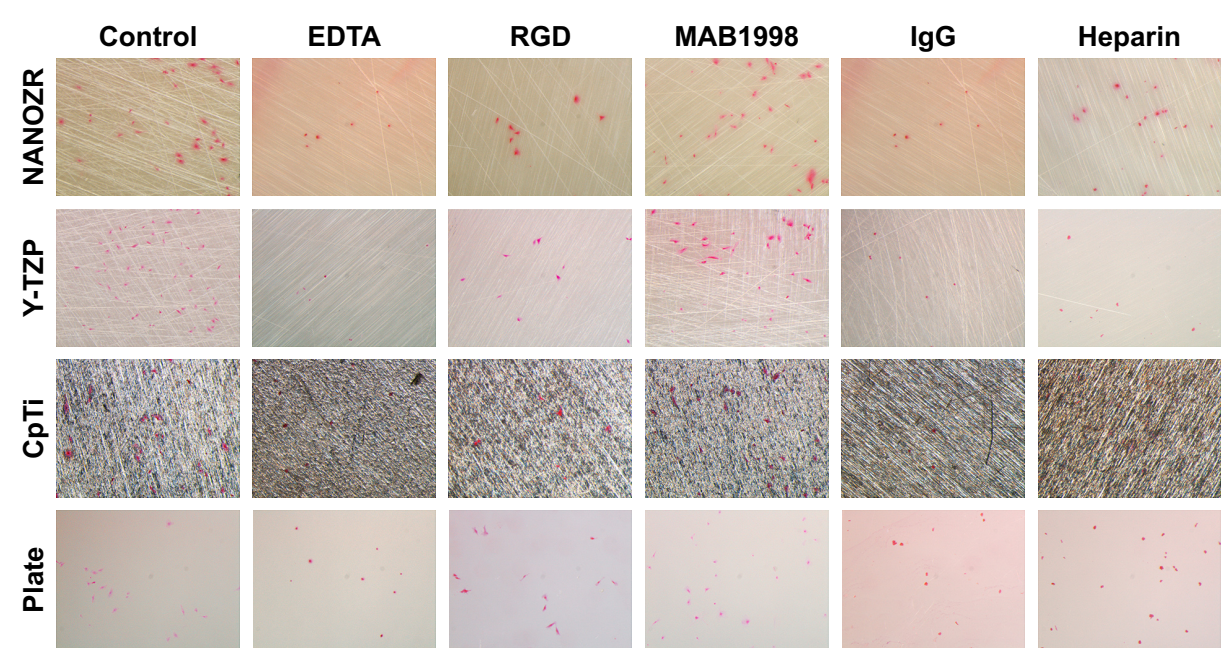

Figure I I Observation of cell morphology by eosin staining in the presence of different inhibitors (Control, EDTA, RGD, MABI998, IgG and Heparin) after 24 hours of incubation. Magnification: $5.6 \times$.

to be an important determinant of a biomaterial's biocompatibility in the in vivo situation. ${ }^{16}$ As reported, zirconia is a biocompatible material with great mechanical properties. ${ }^{17}$ Our previous works reported the similar bioactivity of NANOZR, Y-TZP and CpTi after being polished. ${ }^{18}$ However, the mechanisms of osteoblast adhesion onto zirconia material needed further investigation. In our study, we examined the surface characteristics of NANOZR, Y-TZP and CpTi, and we evaluated the initial osteoblast-like cell response to zirconia and titanium with different inhibitors to elucidate the mechanism of cell attachment.

As documented, cell adhesion is an important parameter by which implant surfaces may be evaluated to determine their suitability for medical use. ${ }^{19}$ To study initial osteoblast adhesion and subsequent differentiation on zirconia surfaces,

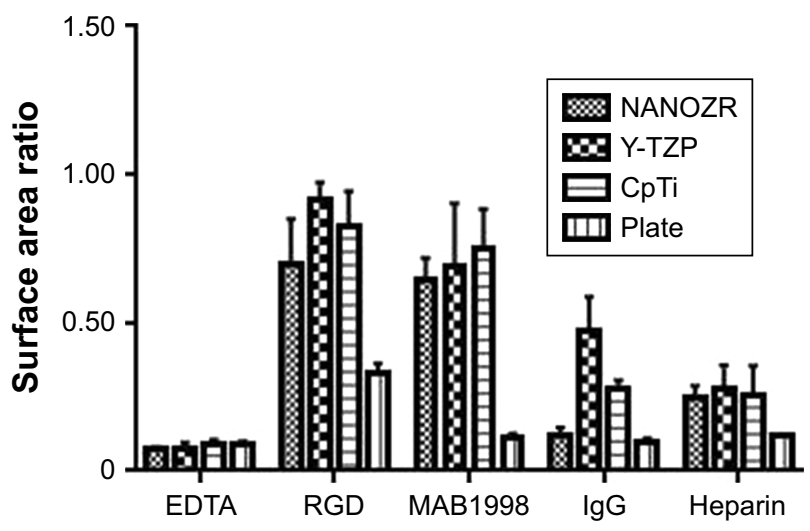

Figure 12 Cell surface area ratio of osteoblasts (MC3T3-EI cells) cultured in the presence of different inhibitors after 24 hours of incubation.

Notes: The cell surface area ratios of RGD and MABI 998 groups are higher than EDTA, IgG and Heparin groups. In addition, the results of NANOZR, Y-TZP and CpTi are better than Plate. the surface characteristics of NANOZR, Y-TZP and CpTi, including chemical composition, surface roughness, wettability and surface energy, were evaluated in this study. The EDS analysis results (Figure 1) demonstrated that no other elements, except carbon, were observed, which may be caused by the polishing process or by exposure to air. SEM images (Figure 2) revealed similar surface scratching after polishing. There were no statistical differences between the $R_{a}$ and $R_{z}$ values of NANOZR and Y-TZP (Figure 3), indicating that the surface roughness of NANOZR and Y-TZP were similar. Furthermore, the contact angles, surface tension and surface energy of the three tested materials (Figure 4) were not significantly different. These results were consistent with previous reports. ${ }^{18}$ Therefore, the different performance of initial cell adhesion and differentiation on NANOZR and Y-TZP surfaces may be due to the difference of their chemical composition.

It is well known that culture media and serum are important for cell growth and lots of proteins are involved in cell adhesion. ${ }^{20}$ However, few studies have examined the different effect of $\alpha$-MEM, FBS and PBS on initial cell adhesion and differentiation on zirconia and titanium surfaces. To specify the effect of culture media and serum, the MC3T3-E1 cells were cultured on the surfaces of NANOZR, Y-TZP and CpTi with three different culture media: PBS, $\alpha$-MEM, and $\alpha$-MEM supplemented with $10 \%$ FBS. According to the different cell morphology, as shown in Figures 5-7, we can conclude that the $\alpha$-MEM is necessary for cell survival and serum protein is helpful for the initial cell adhesion and spreading on zirconia and titanium surfaces. 
The osteoblasts respond to the implant surface through $\mathrm{ECM}$, which plays an important role in osseointegration. ${ }^{21}$ As reported, there are two mechanisms for osteoblast adhesion. ${ }^{22}$ One mechanism is interaction with the RGD motif via cell membrane integrin receptors, and the other is integration between cell membrane heparin sulfate proteoglycans (eg, syndecans) and heparin binding sites on ECM proteins. The integrins and the syndecans are two adhesion receptor families that mediate adhesion, but their relative functional contributions to cell-ECM interactions remain obscure. As reported, the contribution of integrins and syndecans to cell adhesion has largely been demonstrated through the use of inhibitory antibodies. ${ }^{23}$ Therefore, in this study, we evaluated the initial osteoblast-like cell response to NANOZR, Y-TZP and $\mathrm{CpTi}$ in the presence of inhibitory antibodies.

To test the involvement of integrins in cell adhesion onto zirconia and titanium, we administered EDTA, RGD-peptide and monoclonal antibody MAB1998. IgG was used as a control against MAB1998. CCK-8 assay showed significantly higher absorbance value in NANOZR when compared with Y-TZP, CpTi and culture dish Plate in control group, suggesting that the cells show higher proliferation on NANOZR (Figure $8 \mathrm{~A}$ ). Because integrins are activated by divalent cations, integrin-mediated cell adhesion is inhibited in the presence of EDTA. ${ }^{24}$ The absorbance values were decreased in all samples in the presence of EDTA (Figure 8A). This result indicates that divalent cation influx is critical for cell proliferation, so we tested the involvement of integrins. Activated integrins are blocked by synthetic RGD-peptide or antibody which recognizes extracellular region of integrin heterodimer. ${ }^{25}$ Administration of synthetic RGD-peptide, an inhibitor of RGD-type integrins, substantially but to a lesser extent by EDTA, reduced absorbance in NANOZR, Y-TZP and $\mathrm{CpTi}$ (Figure 8B), suggesting that RGD-type integrins regulate cell proliferation on these materials. Interestingly, on the culture dish Plate, cells could maintain their proliferation ability in the presence of RGD-peptide (Figure 8B). This suggests that survival condition on zirconia or $\mathrm{CpTi}$ is harsher than on the culture plate. We next analyzed relation of integrin $\alpha_{2} \beta_{1}$, a representative integrin non-RGD type heterodimer in osteoblasts. ${ }^{26,27}$ Control IgG reduced absorbance when compared with non-treated samples, and blocking of $\alpha_{2} \beta_{1}$ by MAB1998 was enhanced more than in non-treated samples in Y-TZP, CpTi and Plate groups (Figure 8C and D). Enhanced absorbance in NANOZR was not significant compared to other groups (Figure $8 \mathrm{C}$ ), suggesting that suppression of proliferation via $\alpha_{2} \beta_{1}$ is more functional in Y-TZP, CpTi and Plate, but less functional in NANOZR. Further, the cell surface area ratio result was consistent with above analysis (Figure 12). These results also suggest that the ECM-cell adhesion component that is required for normal cell proliferation may be different in NANOZR.

Next we sought to examine the cell adhesion system specific for NANOZR. Because MAB1998 was not effective only in NANOZR, we explored another receptor of $\alpha_{2} \beta_{1}$ ligand. Laminin is a major ligand of $\alpha_{2} \beta_{1}$, and it also binds to syndecan, a heparan sulfate-containing proteoglycan. ${ }^{28} \mathrm{It}$ is remarkable that most ECM molecules possess both integrin-binding and syndecan-binding sites, and a clear synergistic relationship exists between these two families. ${ }^{8}$ We attempted heparin treatment because the heparan sulfate chain is inhibited under the coexistence of heparin. Intriguingly, heparin treatment significantly attenuated CCK-8 absorbance in NANOZR, but not in Y-TZP, CpTi and culture dish Plate (Figure 8), suggesting that heparin-sensitive protein like syndecan specifically promotes cell proliferation on NANOZR.

\section{Conclusion}

In this study, we examined the surface characteristics of NANOZR, Y-TZP and CpTi, and we evaluated the initial response of osteoblast-like cells to them with different inhibitors to elucidate the mechanism of cell attachment on zirconia surfaces. Under the same polishing treatment, the three materials, NANOZR, Y-TZP and CpTi, show similar surface wettability but different surface roughness. Osteoblasts could adhere to the surface of all three materials, and spindle shapes were clearer in serum-containing media compared to PBS and serum-free culture media, suggesting that serum-contained proteins are helpful for the initial cell adhesion and spreading. Cell adhesion and proliferation were disrupted in the presence of EDTA. RGD-peptide interfered with cell proliferation by affecting cell protrusion and stress fibers. Monoclonal antibody against non-RGD type integrin $\alpha_{2} \beta_{1}$ enhanced proliferation in Y-TZP, CpTi and culture dish but not in NANOZR. Cell proliferation on NANOZR was specifically inhibited in the presence of heparin. Furthermore, under heparin administration, spindle shape formation was maintained but actin cytoskeleton was disrupted, resulting in loose cellular spreading. These results suggest that RGD type integrins and heparin-sensitive protein regulate cell morphology and proliferation on NANOZR in coordination, through the regulation of cell polarity and stress fiber formation, respectively.

\section{Disclosure}

The authors report no conflicts of interest in this work. 


\section{References}

1. Bergemann C, Duske K, Nebe JB, et al. Microstructured zirconia surfaces modulate osteogenic marker genes in human primary osteoblasts. J Mater Sci Mater Med. 2015;26(1):1-11.

2. Marchi J, Amorim EM, Lazar DR, Ussui V, Bressiani AH, Cesar PF. Physico-chemical characterization of zirconia-titania composites coated with an apatite layer for dental implants. Dent Mater. 2013;29(9):954-962.

3. Siamantouras E, Hills CE, Squires PE, Liu K-K. Nanomechanical Investigation of Soft Biological Cell Adhesion using Atomic Force Microscopy. Cell Mol Bioeng. 2015;8(1):22-31.

4. Chien CY, Tsai WB. Poly(dopamine)-assisted immobilization of ArgGly-Asp peptides, hydroxyapatite, and bone morphogenic protein-2 on titanium to improve the osteogenesis of bone marrow stem cells. ACS Appl Mater Interfaces. 2013;5(15):6975-6983.

5. Gongadze E, Kabaso D, Bauer S. et, al. Adhesion of osteoblasts to a nanorough titanium implant surface. Int J Nanomed. 2011;6:1801-1816.

6. Liu XS, Luo HJ, Yang H, et al. Palladin regulates cell and extracellular matrix interaction through maintaining normal actin cytoskeleton architecture and stabilizing betal-integrin. J Cell Biochem. 2007; 100(5):1288-1300.

7. Sitasuwan P, Lee LA, Bo P, Davis EN, Lin Y, Wang Q. A plant virus substrate induces early upregulation of BMP2 for rapid bone formation. Integr Biol. 2012;4(6):651-660.

8. Jacquemet G, Humphries MJ, Caswell PT. Role of adhesion receptor trafficking in 3D cell migration. Curr Opin Cell Biol. 2013;25(5): 627-632.

9. Sun SJ, Wu CC, Sheu GT, et al. Integrin $\beta 3$ and CD44 levels determine the effects of the OPN-a splicing variant on lung cancer cell growth. Oncotarget. 2016;7(34):55572.

10. de Marco R, Tolomelli A, Juaristi E, Gentilucci L. Integrin Ligands with $\alpha / \beta$-Hybrid Peptide Structure: Design, Bioactivity, and Conformational Aspects. Med Res Rev. 2016;36(3):389-424.

11. Olivares-Navarrete R, Raz P, Zhao G, et al. Integrin 21 plays a critical role in osteoblast response to micron-scale surface structure and surface energy of titanium substrates. Proceedings of the National Academy of Sciences. 2008;105(41):15767-15772.

12. Pap T, Bertrand J. Syndecans in cartilage breakdown and synovial inflammation. Nat Rev Rheumatol. 2013;9(1):43-55.

13. Theocharis AD, Skandalis SS, Tzanakakis GN, Karamanos NK. Proteoglycans in health and disease: novel roles for proteoglycans in malignancy and their pharmacological targeting. Febs J. 2010; 277(19):3904-3923.
14. Kalin M, Polajnar M. The wetting of steel, DLC coatings, ceramics and polymers with oils and water: The importance and correlations of surface energy, surface tension, contact angle and spreading. Appl Surf Sci. 2014;293:97-108

15. Ko HC, Han JS, Bächle M, et al. Initial osteoblast-like cell response to pure titanium and zirconia/alumina ceramics. Dent Mater. 2007;23(11): 1349-1355.

16. Demetrescu I, Pirvu C, Mitran V. Effect of nano-topographical features of $\mathrm{Ti} / \mathrm{TiO}_{(2)}$ electrode surface on cell response and electrochemical stability in artificial saliva. Bioelectrochemistry. 2010;79(1):122-129.

17. Palmero P, Montanaro L, Reveron H, Chevalier J. Surface Coating of Oxide Powders: A New Synthesis Method to Process Biomedical Grade Nano-Composites. Materials. 2014;7(7):5012-5037.

18. Han JM, Hong G, Matsui $\mathrm{H}$, et al. The surface characterization and bioactivity of NANOZR in vitro. Dent Mater J. 2014;33(2):210-219.

19. Hernández-Ferrer J, Pérez-Bruzón RN, Azanza MJ, et al. Study of neuron survival on polypyrrole-embedded single-walled carbon nanotube substrates for long-term growth conditions. J Biomed Mater Res A. 2014;102(12):4443-4454.

20. Kaukola T, Tuimala J, Herva R, Kingsmore S, Hallman M. Cord immunoproteins as predictors of respiratory outcome in preterm infants. Am J Obstet Gynecol. 2009;200(1):100.e1-100.e1.

21. Minagar S, Wang J, Berndt CC, Ivanova EP, Wen C. Cell response of anodized nanotubes on titanium and titanium alloys. J Biomed Mater Res A. 2013;101(9):2726-2739.

22. Dettin M, Conconi MT, Gambaretto R, et al. Effect of synthetic peptides on osteoblast adhesion. Biomaterials. 2005;26(22):4507-4515.

23. Morgan MR, Humphries MJ, Bass MD. Synergistic control of cell adhesion by integrins and syndecans. Nat Rev Mol Cell Biol. 2007; 8(12):957-969.

24. Barczyk M, Carracedo S, Gullberg D. Integrins. Cell Tissue Res. 2010; 339(1):269-280.

25. Spassov DS, Wong CH, Sergina N, et al. Phosphorylation of Trask by Src kinases inhibits integrin clustering and functions in exclusion with focal adhesion signaling. Mol Cell Biol. 2011;31(4):766-782.

26. Reed NI, Tang YZ, Mcintosh J, et al. Exploring $N$-Arylsulfonyl-1-proline Scaffold as a Platform for Potent and Selective $\alpha v \beta 1$ Integrin Inhibitors. ACS Med Chem Lett. 2016;7(10):902-907.

27. Lam MT, Longaker MT. Comparison of several attachment methods for human iPS, embryonic and adipose-derived stem cells for tissue engineering. J Tissue Eng Regen Med. 2012;6 Suppl 3:s80-s86.

28. Dalrymple N, Mackow ER. Productive dengue virus infection of human endothelial cells is directed by heparan sulfate-containing proteoglycan receptors. J Virol. 2011;85(18):9478-9485.
International Journal of Nanomedicine

\section{Publish your work in this journal}

The International Journal of Nanomedicine is an international, peerreviewed journal focusing on the application of nanotechnology in diagnostics, therapeutics, and drug delivery systems throughout the biomedical field. This journal is indexed on PubMed Central,

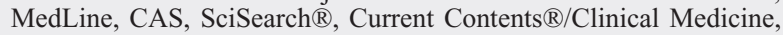

\section{Dovepress}

Journal Citation Reports/Science Edition, EMBase, Scopus and the Elsevier Bibliographic databases. The manuscript management system is completely online and includes a very quick and fair peer-review system, which is all easy to use. Visit http://www.dovepress.com/ testimonials.php to read real quotes from published authors. 